\title{
Impacto de los medios de comunicación masiva en una campaña antitabaco
}

\author{
Raúl H Sansores, MD, MSC, ${ }^{(1)}$ Fernanda Giraldo-Buitrago, MD, ${ }^{(1)}$ \\ Fabiola Valdelamar-Vázquez, MD, ${ }^{(1)}$ Alejandra Ramírez-Venegas, MD, MSc, ${ }^{(1)}$ Ricardo A Sandoval, Dr. ${ }^{(1)}$
}

\begin{abstract}
Sansores RH, Giraldo-Buitrago F, Valdelamar-Vázquez F, Ramírez-Venegas A. Impacto de los medios de comunicación masiva en una campaña antitabaco. Salud Publica Mex 2002;44 supl 1:S101-S108. El texto completo en inglés de este artículo está disponible en: http://www.insp.mx/salud/index.html
\end{abstract}

\section{Resumen}

Objetivo. Determinar en México el impacto de los medios de comunicación masiva (MCM) en el proceso de dejar de fumar. Material y métodos Evaluamos, entre junio de 1998 y mayo de 1999, el efecto de una campaña en los MCM de México, así como el de estrategias alternas, comparando el promedio mensual de ventas de todos los productos auxiliares para dejar de fumar antes y después del lanzamiento de un Parche $N$ uevo de nicotina. Se usó t pareada 0 de Student para comparar las ventas. Resultados Las ventas totales aumentaron de $24 \quad 206 \pm 4558$ a $55604 \pm 8993$ $(p<0.0001)$. Estimamos que 1853 fumado res intentaron dejar de fumar y 96 lo consiguieron diariamente con un solo producto después de la promoción. Estrategias alternas para conseguir resultados similares indican que programas de una institución del sector público podrian conseguir que seis personas dejaran de fumar y 501 lo intentaran diariamente. Conclusiones Los MCM tienen un efecto poderoso en el proceso para dejar de fumar y la inclusión de más instituciones del sector público podría igualar lo obtenido por el sector privado. El texto completo en inglés de este artículo está disponible en: http://www.insp.mx/salud/ index.html

Palabras clave: tabaquismo; campañas antitabaco; medios de comunicación de masa; promoción de la salud; México

\author{
Sansores RH, Giraldo-Buitrago F, \\ Valdelamar-Vázquez F, Ramírez-VenegasA. \\ The impact of mass media \\ on an anti-tobacco campaign. \\ Salud Publica Mex 2002;44 suppl 1:S101-S108. \\ The English version of this paper \\ is available at: http://www.insp. mx/salud/index.html
}

\begin{abstract}
A bstract
Objective To assess the impact of the mass media (MM) on smoking cessation process in Mexico. Material and Methods. Between June 1998 and May 1999, the effects of an anti-smoking mass media campaign and alternative strategies were evaluated, by comparing the monthly sales average of all smoking-cessation aid products before and after marketing a new nicotine patch. Student's t paired and unpaired t tests were used to compare sales. Results. Total sales increased from $24206 \pm 4558$ to $55604 \pm 8993$ $(p<0.0001)$. It was estimated that 1853 smokers tried to quit and 96 per day succeeded with a single product after the campaign. Alternative strategies to get similar results indicate that the programs of a single public sector institution could help 501 persons attempt quitting smoking and six to accomplish it per day. Conclusions The mass media have a powerful effect on smoking cessation practices; the involvement of more public institutions may accomplish similar results as the private sector. The English version of this paper is available at:http://www.insp.mx/salud/index.html
\end{abstract}

Key words: smoking; anti-tobacco smoking campaigns; mass media; health promotion; Mexico

(1) Departamento de Investigación en Tabaquismo y EPO C. Instituto Nacional de Enfermedades Respiratorias, Secretaría de Salud, México.

Fecha de recibido: 30 de marzo de 2001 - Fecha de aprobado: 22 de octubre de 2001

Solicitud de sobretiros: Raúl H. Sansores. Departamento de Investigación en Tabaquismo y EPO C. Instituto N acional de Enfermedades Respiratorias, SSA. Calzada de Tlalpan 4502, 14080, México, D. F., México. Correo electrónico: rhsansores@ aol.com. 
os fumadores tienen una probabilidad dos veces mayor de morir en forma prematura en comparación con los individuos que no fuman. Un número creciente de enfermedades forman la lista actual de los daños a la salud causados por el tabaquismo. ${ }^{1}$ Las estimaciones actuales revelan que en el mundo cuatro millones de personas mueren anualmente por alguna enfermedad asociada con el consumo de tabaco. ${ }^{2}$ En México, el fenómeno es causa de más de 40000 muertes al año. Es decir, el tabaquismo es una de las peores enfermedades en la historia de la humanidad. A pesar de que estas estadísticas no son totalmente ignoradas por la población, más de $27 \%$ de los mexicanos fuma. ${ }^{3}$ La pregunta que surge es ¿por qué la gente fuma? La adicción a la nicotina es una explicación parcial por la que los fumadores actuales siguen fumando. Sin embargo, hay menos información de los motivos que preceden a la adicción. Es decir, ¿por qué se inician los jóvenes?, ¿por qué los adultos se resisten a cuando menos intentar dejar de fumar? La respuesta parcial a estas preguntas se encuentra en las estrategias que la industria tabacalera utiliza para ganar nuevos fumadores y mantener a los existentes.

La industria tabacalera se ha convertido en el ejemplo de las empresas que han logrado, en un periodo relativamente corto de tiempo, un número impresionante de ventas alrededor del mundo. ${ }^{4}$ En la sociedad contemporánea los productos de la industria tabacalera son ampliamente conocidos. Recientes evidencias demuestran que, por ejemplo, el logotipo de alguno de ellos es reconocido por los niños desde los tres años de edad, y aquellos que tienen más de seis años los reconocen más fácilmente que el logotipo de Disney. ${ }^{5}$ Asimismo, sus mensajes se pueden observar en una gran cantidad de personajes y eventos de la vida cultural y deportiva, al punto que poseer, exhibir o usar alguno de los productos de la industria tabacalera se ha hecho algo deseable y anhelado por los jóvenes adolescentes de nuestra moderna sociedad. La consecuencia de esta extensa difusión es una gran venta de sus productos. ${ }^{6}$

La industria tabacalera ha logrado crear esta demanda de sus productos mediante una vigorosa e ingeniosa campaña de mercado, utilizando todos los medios de difusión masiva que en su momento histórico fueran más importantes. Para tener una idea, en 1996 la industria tabacalera invirtió 5.6 billones de dólares en sus mensajes de promoción. ${ }^{7}$ Desde la perspectiva del creador de imágenes, la industria tabacalera y otras grandes corporaciones son un paradigma de quienes bien vale la pena aprender la forma y meca- nismos de persuadir en forma masiva cambios de conducta y actitud.

Por lo tanto, desde el punto de vista de la salud pública, basados en el antecedente del éxito en las ventas conseguido por la industria tabacalera utilizando los medios de comunicación masiva, partimos de la hipótesis de que una campaña antitabaco que utilice los mismos instrumentos, podría obtener resultados de igual magnitud, pero en dirección contraria a la del consumo. Para probar nuestra hipótesis, analizamos las ventas conseguidas por la industria farmacéutica sobre los productos auxiliares para dejar de fumar antes y después de una campaña promocional utilizando los medios de comunicación masiva. Para ello aprovechamos la coyuntura que se vivió en México con el lanzamiento de un producto comercial que se utiliza como auxiliar en el proceso para dejar de fumar. Este producto rompió con el esquema tradicional de promoción en consultorios médicos y lanzó una ambiciosa campaña en los medios. El objetivo de este trabajo es describir el efecto de dicha campaña promocional y alternativamente analizar el impacto teórico de una campaña masiva popular basada en una galería de carteles. Finalmente, en este trabajo comparamos el efecto de estas dos formas de campaña con los resultados obtenidos en la Clínica de Ayuda para Dejar de Fumar, del Instituto Nacional de Enfermedades Respiratorias (INER) de la Secretaría de Salud. Nuestros hallazgos y conclusiones respecto del número total de personas que intenta dejar de fumar y el número que realmente lo consigue es teórico y producto de especulaciones nuestras. Estrictamente hablando, no hay forma de probar que aquellos que compararon una cantidad indeterminada de parches realmente dejaron de fumar. Nuestras estimaciones llevan a resultados que deben considerarse en forma hipotética.

\section{Material y métodos}

\section{A nuncios televisivos que promueven productos auxiliares para dejar de fumar}

El 31 de mayo de 1999 se lanzó en México un parche que provee nicotina en forma transdérmica como auxiliar en el proceso de dejar de fumar (en adelante Parche Nuevo). El lanzamiento se hizo a través de anuncios directos en los dos canales de televisión que capturan el mayor auditorio en México. Se analizó el tiempo-aire invertido durante un año a partir de su lanzamiento. Los anuncios, en forma individual, consistían en mensajes de 30 a 60 segundos de duración, y 
en general hacían hincapié en la salud individual y el bienestar familiar asociados con el abandono del tabaquismo. Asimismo, el mensaje se aseguraba de mencionar que con los "parches" esto se conseguiría más fácilmente y con tranquilidad. Además, los promotores de los parches organizaron que en algunos de los programas con mayor auditorio se hicieran entrevistas a líderes de opinión, para promover directa e indirectamente su producto.

\section{Programas radiofónicos para promover una cultura libre de humo de tabaco}

A través de unos programas pagados y otros no, se consiguieron entrevistas en las principales estaciones radiodifusoras de México. Las entrevistas tuvieron como objetivo mencionar cuatro aspectos fundamentales en la lucha antitabaco: a) subrayar el hecho de que el tabaquismo es una adicción y que dentro del manual de diagnóstico de las enfermedades psiquiátricas, éste ya se considera una enfermedad; b) que el consumo del tabaco es responsable de un número importante de enfermedades, e invariablemente se enumeraron las más comunes; c) que esta adicción es la responsable de que los fumadores no puedan dejar de fumar, a pesar de saber que está asociada con las enfermedades mencionadas, y d) que al generar tanto una dependencia física como psicológica, el fumador requiere, para dejar de fumar, una terapia que considere estos dos aspectos. El nombre comercial de los parches no se mencionaba en el programa, a menos que el conductor o el auditorio lo preguntaran directamente. La intervención radiofónica se cuantificó como tiempoaire total.

\section{Entrevistas en la prensa}

Se consiguieron entrevistas en los principales periódicos de circulación diaria y en revistas. En ellas, se trataban diferentes aspectos, pero siempre se abordó el tema de las terapias para dejar de fumar. En términos generales, las entrevistas siguieron el mismo formato de las radiofónicas. Esta intervención se cuantificó como líneas totales publicadas.

\section{Medición del impacto}

El análisis del impacto de esta promoción (televisiva, radiofónica y escrita) se determinó comparando las ventas de todos los productos auxiliares para dejar de fumar, conseguidas antes del lanzamiento del parche, con las obtenidas un año después de su lanzamiento. Determinamos el promedio mensual de ventas de los productos, realizadas de enero a mayo de 1999 que hasta ese momento existían en el mercado mexicano (chicles de nicotina y dos parches de nicotina), y las comparamos con el promedio mensual de ventas de junio de 1999 a mayo de 2000. Esta última estimación ya incluía las ventas conseguidas un año después del lanzamiento del Parche Nuevo. De este modo se podría inferir que la diferencia en ventas fue por efecto de la campaña promocional, y no necesariamente por la introducción del parche, pues ya existían dos en el mercado mexicano. Usamos como fuente la información mensual del International Marketing Services (IMS), ${ }^{8}$ una agencia privada que en forma mensual brinda servicios informativos sobre las ventas conseguidas por los diferentes laboratorios farmacéuticos. Cada una de las ventas de alguno de los productos disponibles comercialmente en el mercado la definimos como intento para dejar de fumar. Asimismo, utilizando la información obtenida de las ventas del nuevo parche, hicimos una estimación especulativa del número potencial de fumadores que dejaron de hacerlo, considerando las características de este producto, a saber: este Parche Nuevo tiene tres presentaciones comerciales cuya diferencia entre sí es el contenido progresivamente menor de nicotina ( $21 \mathrm{mg}, 14 \mathrm{mg}$ y $7 \mathrm{mg}$ ); las tres se venden al público en cajas que contienen siete parches cada una y la casa comercial recomienda que si el fumador que está intentado dejar de fumar consume 10 o más cigarros por día, entonces debe utilizar durante seis semanas parches de $21 \mathrm{mg}$, en tanto que si fuma menos de 10 debe empezar con los parches de $14 \mathrm{mg}$ y usarlos durante seis semanas. En el primer caso debe continuar con dos semanas de $14 \mathrm{mg}$ y finalizar con los de $7 \mathrm{mg}$ durante dos semanas más. Si empieza con los de $14 \mathrm{mg}$, debe finalizar con dos semanas más utilizando los parches de $7 \mathrm{mg}$. Es decir, la compra de parches de $7 \mathrm{mg}$ implica que un fumador cursó cuando menos por una de las etapas previas (la de 21 o la de $14 \mathrm{mg}$ ). Por lo tanto, la posibilidad de que un sujeto que llegó hasta la compra de los parches de 7 $\mathrm{mg}$, realmente haya dejado de fumar, es mucho mayor que la de aquél que no llegó a comprar esta dosis. Anticipando todas las inexactitudes de esta posibilidad, asumimos que la venta total de los parches de $7 \mathrm{mg}$, dividida entre dos (asumiendo que un fumador tiene que comprar dos paquetes en la última etapa) es igual al número de individuos que realmente dejaron de fumar. Esta cifra se podría expresar con un denominador temporal como día, mes o año. 


\section{Mecanismos alternos al de los medios masivos para campañas antitabaco}

Anuncios del sector salud en los medios de comunicación masiva parcialmente financiados por la industria farmacéutica

La misma empresa que en 1999 lanzó al mercado los parches aceptó financiar la producción de anuncios adaptados para la televisión. En ellos se estimulaba a los fumadores a dejar de fumar mediante diferentes incentivos. No se mencionó el nombre de ningún producto comercial y solamente apareció el logotipo del Instituto Nacional de Enfermedades Respiratorias (INER) y el de la Secretaría de Salud. En uno de los anuncios se describen los daños a la salud, asociados con el consumo de tabaco, con la imagen de una niña que llora desconsolada porque su papá está hospitalizado en una unidad de terapia intensiva a causa de alguna enfermedad relacionada con el consumo de tabaco. El segundo anuncio empieza en una fiesta infantil en la cual los niños están corriendo y jugando. Después aparece el niño festejado: en el momento de partir su pastel no puede apagar las velitas porque desarrolla síntomas de asma que parecen provocados por la exposición involuntaria al humo del cigarro, que proviene de su mamá, quien aparece fumando. El impacto de esta intervención se cuantificó por el número de llamadas telefónicas y visitas que se recibieron en la Clínica de Ayuda para Dejar de Fumar, del INER.

\section{Campaña antitabaco con carteles}

La segunda estrategia utilizó una exposición de 20 carteles. Cada uno de ellos tiene una imagen visualmente atractiva y un título que recuerda algún refrán popular de los que se utilizan en México. Las características de ésta, así como de cada cartel, se han publicado en otra parte. ${ }^{9}$ Brevemente, describiremos los métodos utilizados. Se tomaron 20 a 30 visitantes consecutivos de 45 exposiciones diferentes y consecutivas. Este abordaje permitió incluir distintas poblaciones y eliminar, al menos parcialmente, el sesgo posible de tomar una sola población. A pesar de este cuidado, creemos que en todo caso la encuesta recoge el testimonio de un sector de la población, el que está interesado en ver una exposición de este tipo. A la fecha, los carteles se han expuesto en más de mil foros diferentes en todo el país. A cada una de las exhibiciones asisten en promedio más de mil personas cuando éstas se exponen por un tiempo limitado. Para la medición del impacto de esta exposición, se aplicó una encuesta a 1177 visitantes que en forma consecutiva asistieron a la galería. ${ }^{9}$
Los resultados obtenidos de esa encuesta, los utilizamos considerando el número total de personas que la han visitado en un año. De esos resultados hicimos estimaciones del número de personas que dejaron de fumar a partir de la influencia de la exposición.

Efecto del programa que se lleva en la Clínica para Dejar de Fumar, del INER

De la evaluación de la utilidad del programa de la clínica del INER ${ }^{10}$ se ha estimado su efecto real considerando a todas las personas que acuden y solicitan formalmente ayuda. ${ }^{11}$ Utilizando esa información, estimamos su impacto en términos del número de personas que dejan de fumar o lo han intentado. A cada una de las visitas (personas) recibidas en nuestra clínica solicitando ayuda para dejar de fumar las consideramos intentos, y como éxito solamente a aquellos que al año dejaron de fumar.

\section{Resultados}

El tiempo-aire transmitido para promocionar los productos para dejar de fumar durante el periodo estudiado (junio de 1999 a mayo de 2000), fue de 154 minutos con 16 segundos para la televisión y de 434 minutos para la radio. El número de líneas escritas en los diferentes medios de prensa fue de 14 077, $3 / 4$ planas y cinco páginas. El efecto de esta estrategia promocional, considerando el número de unidades vendidas, se puede apreciar en el cuadro I y se esquematiza en la figura 1 . Tomando en cuenta que cada venta por unidad de 21 o $14 \mathrm{mg}$ es un intento de dejar de fumar, en el cuadro II se puede observar que esta venta equivale a 1853 intentos para dejar de fumar por día. En el mismo cuadro se puede observar que debido a que, respecto de las piezas de $7 \mathrm{mg}$ la venta mensual es en promedio de 5760 unidades; esta cantidad, al considerar 30 días y dividirse entre dos, proporciona un total de 96 personas que diariamente dejaron de fumar. En la figura 2 se muestra el impacto del programa "entre colillas", donde se puede observar que $41 \%$ de los visitantes de la exposición son fumadores y de ellos $84 \%$ dejaría de fumar después de haber visto la exposición. Considerando que durante un año 500000 personas han acudido a la galería, un total de 205000 fumadores vieron la exposición. De ellos, 172000 (472 al día), según los resultados de nuestra encuesta, ${ }^{9}$ intentarían dejar de fumar al año. En el cuadro II se muestra el efecto de este programa con un ánimo optimista, es decir, que $10 \%$ de esos fumadores realmente dejara de fumar, sería igual a que 47 personas diariamente, y en forma hipotética, dejaran de 


\section{Cuadro I}

\section{Venta de PROductos aUXILIARES PARA DEJAR DE FUMAR ANTES Y DESPUÉS DE UNA CAMPAÑA EN LOS MEdios de COMUNICACIÓN MASIVA. MÉXICO, 1998-2000}

\begin{tabular}{lccccr} 
& $\begin{array}{c}\text { Junio/1998 a mayo/1999 } \\
\text { Promedio } \pm \text { DE }\end{array}$ & $\begin{array}{c}\text { Junio/1999 a mayo/2000 } \\
\text { (Mínimo-máximo) }\end{array}$ & Promedio \pm DE & (Mínimo-máximo) & $p$ \\
Venta Total & $24206 \pm 4,558$ & $(19651-35843)$ & $55604 \pm 8993$ & $(41617-69355)$ & 0.00001 \\
\hline Parche 1 & $23071 \pm 4543$ & $(18796-34962)$ & $24720 \pm 2801$ & $(20,166-29747)$ & 0.346 \\
\hline Parche 2 & $1016 \pm 305$ & $(453-1529)$ & $298 \pm 84$ & $(200-463)$ & 0.001 \\
\hline Parche 3 & $1.6 \pm 3$ & $(0-9)$ & $4 \pm 4$ & $(0-12)$ & 0.30 \\
\hline Parche N uevo & (No existía) & & $30700 \pm 9089$ & $(15454-43651)$ & $0.06^{\ddagger}$
\end{tabular}

Fuente: International Marketing Services (IMS). Reporte mensual (ver referencia 8)

* Se refiere a la comparación de ventas del mismo producto en diferentes periodos. Se usó la t para muestras pareadas

₹ Se refiere a la comparación de las ventas de Parche Nuevo con las de Parche 1 para el mismo periodo de tiempo. Se usó la prueba t de Student para muestras independientes

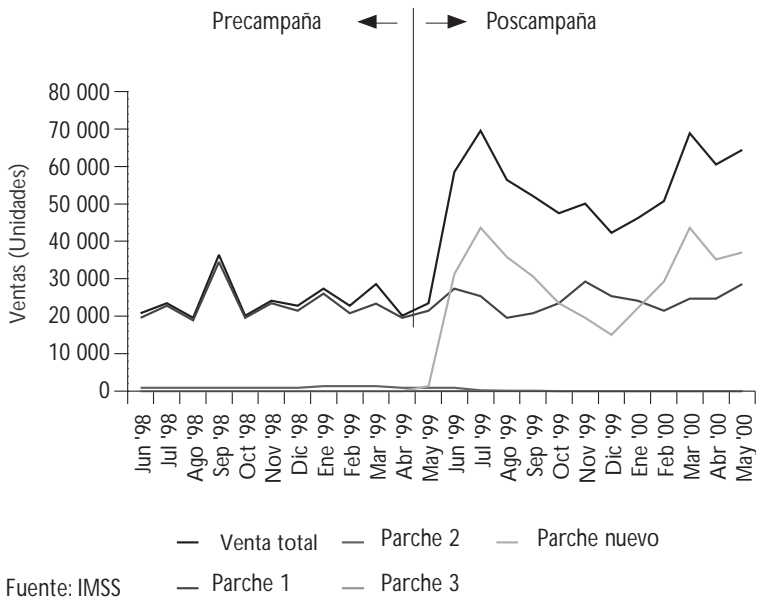

Figura 1.Ventas mensuales de productos auxiliares PARA DEJAR DE FUMAR

fumar. Asimismo, se muestra el efecto de un cálculo pesimista, es decir, que solamente $1 \%$ de esa población lo conseguirá, o sea, cinco personas al día. En el mismo cuadro se muestra el efecto de la clínica del INER. ${ }^{10,11}$ Esta información representa el efecto de la promoción tradicional que se hace a sus programas antitabaco, y el efecto de un anuncio televisivo que lleva el logotipo del INER. En este cuadro consideramos como intentos a todos aquellos que fueron a pedir información directamente o llamaron por teléfono para solicitar información para dejar de fumar. Les llamamos pagados porque fueron directamente a la clínica e hicieron, por lo tanto, una inversión de tiempo y trans-

\begin{tabular}{|c|c|c|}
\hline \multicolumn{3}{|c|}{$\begin{array}{c}\text { Cuadro II } \\
\text { IMPACTO PROMEDIO DIARIO DE UNA CAMPAÑA } \\
\text { EN LOS MEDIOS DE COMUNICACIÓN MASIVA EN EL } \\
\text { PROCESO DE DEJAR DE FUMAR. MÉXICO, 1999-2000 }\end{array}$} \\
\hline & Medios & $\begin{array}{c}\text { INER } \\
\text { "Entre Colillas" }\end{array}$ \\
\hline mero de & 807 & 7 \\
\hline imero de intentos (poscampaña) ${ }^{\ddagger}$ & 1853 & 21 \\
\hline ímero de intentos (de palabra) & & \\
\hline \multicolumn{3}{|l|}{ úmero de personas que dejan de fumar: } \\
\hline Con los medios (3a etapa/Parche $\mathrm{N}$ uevo) & $96^{\alpha}$ & \\
\hline Plan optimista & & $47+1^{\neq}$ \\
\hline Plan pesimi & & $5+0.3^{\infty}$ \\
\hline \multicolumn{3}{|c|}{$\begin{array}{l}\text { * Periodo:junio 1998-mayo 1999. Para "Medios" incluye ventas con todos } \\
\text { los productos. Para el Instituto N acional de Enfermedades Respiratorias } \\
\text { (IN ER), Ilamadas telefónicas para dejar de fumar. Datos no publicados } \\
\text { \# Periodo:junio 1999-mayo 2000. Para“"Medios" incluye ventas con todos } \\
\text { los productos. Para IN ER: efecto de los mensajes televisivos } \\
\text { § Esfuerzo adicional del visitante a la galería al contestar un cuestionario } \\
\text { \# Esfuerzo adicional del individuo que acudió a IN ER al someterse a una } \\
\text { entrevista } \\
\text { \& Sólo incluye Parche N uevo } \\
\text { ₹ Abstinencia esperada a un año (número total de personas que intentan } \\
\text { dejar de fumar). Referencia } 10 \\
\text { "Abstinencia real a un año (35\% del total de personas que intentan dejar } \\
\text { de fumar). Referencia } 10\end{array}$} \\
\hline
\end{tabular}

porte. En el mismo periodo en que se analizaron las ventas del Parche Nuevo, aproximadamente 3000 personas acudieron a nuestra clínica. De ellas solamente $10 \%$ se inscribió a nuestro programa cognitivo conductual, y considerando que solamente $35 \%$ de ellos se mantiene en abstinencia un año después, solamente 


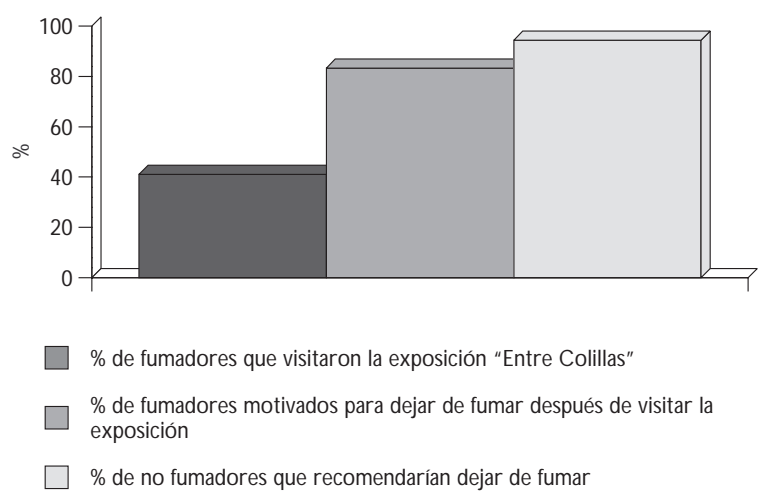

Fuente:Tobacco Control 1998;7(4):338-339.

Figura 2. Impacto de la galería "Entre Colillas" EN EL PROCESO DE DEJAR DE FUMAR

registramos como individuos que dejaron de fumar a 70 de ellos. ${ }^{11}$ A los que solamente llamaron por teléfono los consideramos como intentos de palabra cuando dieron su nombre y teléfono, y no fue considerado en esta descripción cuando no lo hicieron. El número de llamadas aumentó después de que aparecieron los anuncios televisivos de la promoción que resultó de nuestra alianza con la industria farmacéutica. En el cuadro se muestra que se triplicaron (de 7 a 21) las llamadas que diariamente se recibieron un día después de transmitir el anuncio. Estas llamadas tenían como objetivo solicitar información para dejar de fumar.

\section{Discusión}

Este trabajo muestra que los medios de comunicación masiva son instrumentos poderosos para promover las campañas antitabaco, y en particular para estimular en los fumadores el deseo de intentar dejar de fumar. En un año la promoción llevada a cabo por la industria farmacéutica mostró tener más impacto real, en términos del número de personas que dejaron de fumar en un año, que todos los programas desarrollados por el Instituto Nacional de Enfermedades Respiratorias en el mismo periodo. Es decir, mientras que el impacto de la promoción masiva consiguió casi 2000 intentos diarios y que 96 personas consiguieran exitosamente dejar de fumar, también diariamente, los programas del INER consiguieron, en el mismo lapso 472 intentos (172 000 fumadores que dijeron que dejarían de fumar entre 365 días) y $48(47+1)$ casos de éxito en un plan optimista, y $5.3(5+0.3)$ en un plan pesimista. Aunque deben guardarse todas las reservas para estas estimaciones, desde cualquier ángulo o en cualquiera de las direcciones que se quieran examinar, vale la pena hacer algunas consideraciones al respecto.

Con relación al programa "Entre Colillas", se cuantificaron como intentos a todos los fumadores que hicieron el esfuerzo de ir a la galería y de contestar la encuesta. Respecto del INER se consideraron como intentos a todos aquellos que fueron o llamaron telefónicamente, y respecto a los medios de comunicación masiva, a todos aquellos que compraron cualquier producto y no solamente las presentaciones del Parche Nuevo. En cambio para el análisis del número de personas que dejaron de fumar, solamente consideramos las ventas de la tercera etapa de este parche. En este sentido, los números subestiman el éxito global de la campaña en los medios, pero también los alcances potenciales del sector salud porque solamente se muestra la campaña de una de sus instituciones como es el INER.

Respecto de la campaña en los medios, no cabe duda que cualquier programa nacional de salud que utilice los medios de comunicación masiva tendrá un gran impacto. Este efecto es en realidad mayor en la medida en la cual se incremente el número de veces que se anuncie el producto, del medio utilizado y del tipo y calidad del promocional en cuestión. En el caso de los anuncios del Parche Nuevo, utilizaron los canales de televisión más vistos en México. Asimismo, cuidaron que la producción fuera comercialmente atractiva. Es decir, como estrategia de mercadotecnia, su campaña fue un éxito para la compañía, según se observa en el número de ventas. No obstante, no cabe duda de que también fue un éxito para el sector salud, puesto que uno de los principales objetivos de nuestra campaña es conseguir que los fumadores dejen de fumar.

De este análisis se puede concluir que el uso de los medios de comunicación masiva con campañas de promoción similares a las de cualquier campaña de mercado, como las que utiliza la industria tabacalera, son exitosas y podrían utilizarse en la promoción de la salud. Probablemente el antecedente más importante es el de California con el proyecto conocido como la propuesta 99. En él se planteó un programa en el que, mediante imágenes televisivas, se desalentaría el consumo y la iniciación en él. Para ello, se utilizaron diferentes estrategias. Cada una de ellas fue evaluada de acuerdo con su impacto. ${ }^{12}$ Sin duda la que causó el mayor éxito es la que se conoce como de manipulación. En ella se escenificaron con ideas diversas la forma como la industria tabacalera manipula las aspiraciones y los anhelos de los jóvenes para inducirlos e incitarlos a experimentar con el cigarro. La reacción 
obtenida por parte de los jóvenes fue de coraje y de rechazo hacia los productos de la industria tabacalera. Por lo tanto, se consiguió el objetivo de desalentar el consumo.

Este efecto de desaliento en el consumo de cigarros, conseguido con una campaña antitabaco, utilizando los medios, se puede observar claramente en el trabajo de Goldman y Glantz. ${ }^{12}$ En él, se puede contrastar el efecto de los medios sobre las campañas tradicionales. Mientras que la aplicación de programas de prevención tradicionales (es decir, aquellos que están basados en la distribución de folletos médicos, pláticas y conferencias) tienen un efecto débil, la introducción de la campaña televisiva realmente golpeó el consumo. El primer efecto se logró en 1992 y fue máximo en 1996. En ese periodo se dejaron de vender 2 billones de cajetillas al año.

\section{Inconvenientes económicos para el desarrollo de campañas utilizando los medios de comunicación masiva y el diseño de estrategias alternativas}

El éxito de la campaña antitabaco en California no tiene precedentes. Sin embargo, el costo, al igual que el de las campañas de la industria tabacalera, también es millonario. Así, de acuerdo a Goldman y Glantz ${ }^{12}$ el precio per capita por año fue de 50 centavos de dólar. Es decir, cada año se invertirían 50 millones de dólares por cada 100 millones de habitantes. Una campaña de esa magnitud en México tendría un costo de $500 \mathrm{mi}-$ llones de pesos anuales. Debido a que el proyecto podría no ser factible, en México y probablemente en otros países de Latinoamérica, se tienen que desarrollar estrategias alternativas. Bajo la premisa de que los medios actúan como el motor de cualquier campaña y las imágenes como sus promotores, analizamos los efectos potenciales de dos campañas alternas. Una a través de la televisión, cuya estrategia alterna fue la fuente de financiamiento, y la otra a través de carteles, cuya estrategia alterna se basó en el tipo de imagen y su forma de promoción. Para la televisión, se diseñaron un par de anuncios utilizando alguna de las modalidades empleadas en California y que se describieron sucintamente en los métodos. Desafortunadamente no se elaboró un programa específico para la medición del impacto de estos comerciales. Sin embargo, considerando que ni siquiera se puso el número telefónico del INER en los comerciales, y que el número de llamadas telefónicas se triplicaron, se puede inferir un gran impacto promocional. Además, si consideramos que solamente estamos tomando en cuenta las llamadas capturadas en una sola línea telefónica directa, que además no es exclusiva para ese fin, el impacto debe ser necesariamente mayor. La asociación del sector salud con la iniciativa privada no goza de gran popularidad dentro del sector público. Quizás porque parece que contribuimos a incrementar sus ventas o quizás porque no hay un beneficio económico de ellas. Tal vez es tiempo de renovar esa perspectiva independientemente de las razones de ellas, porque lo que se puede conseguir de una alianza estratégica con la iniciativa privada, al menos para el caso de la lucha contra el tabaco, va más allá de lo que las instituciones públicas en forma aislada pueden conseguir. Pero debe ser claro que la alianza propuesta es con el sector privado que tiene intereses comunes a los nuestros, es decir, disminuir el tabaquismo.

Por otro lado, la exposición de carteles a través del programa conocido como "Entre Colillas", sin duda tiene gran alcance popular. El hecho de conseguir medio millón de espectadores voluntarios en un año sugiere que ha capturado la atención de un sector importante de la población. Si consideramos que la prevalencia de fumadores en México es de $27.7 \%$ de quienes tienen entre 12 y 65 años de edad, el hecho de que $41 \%$ de los asistentes a la galería sean fumadores significa que cuando menos están ocurriendo dos fenómenos que debemos analizar al respecto de este tipo de exposiciones. El primero, parece que éstas son realmente atractivas y el número de sus espectadores aumenta con el paso de los meses. El segundo, parece ser que los fumadores buscan información respecto del tabaquismo, es decir, pueden estar en la fase de contemplación dentro del ciclo del fumador. ${ }^{13}$ Tradicionalmente, el fumador que se encuentra en la fase de precontemplación no quiere saber nada de los daños a la salud relacionados con el tabaquismo. En realidad, se encuentra en un periodo de negación. El hecho de acudir y referir en la encuesta que después de haberse expuesto a la información dejarían de fumar, significa que están contemplando la posibilidad y se requiere trabajar más con ellos, es decir, se requieren más programas de este tipo. En este trabajo hemos descrito lo que se ha conseguido por una sola institución. Las cifras que hemos expuesto podrían multiplicarse por el número de instituciones que llevaran a cabo un programa similar. El costo de estos programas cabe dentro del presupuesto de cualquier institución que quiera echar a andar un programa permanente en sus instalaciones. Lo descrito en este artículo tiene que ver con exposiciones transitorias. Las instituciones podrían adquirir sus propias colecciones para exhibirlas continuamente. Probablemente el estímulo para no fumar o dejar de fumar sería mayor. Es evidente que, a pesar de sus expectativas, los alcances de 
esta campaña son limitados si se los compara con los de una campaña que utiliza medios de comunicación masiva como la televisión y la radio. Sin embargo, el costo, al igual que los alcances de sendas campañas es diferente y proporcional.

Cuando comparamos lo conseguido por los medios con los programas de la Clínica para Dejar de Fumar, del INER, parecería que se intenta subestimar la labor. Nada más lejos de ello. El objetivo de este análisis es subrayar el efecto potencial del sector salud ante la labor de una sola institución. Si 10 instituciones lograran este impacto, tendríamos 480 ex fumadores al día, en vez de 48, y si 100 instituciones lo hicieran, nos acercaríamos a la cifra de 4800 ex fumadores por día. Es decir, la cifra sería directamente proporcional al esfuerzo de cada una de las instituciones de salud existentes en el país.

\section{Conclusiones}

El análisis de estos fenómenos ilustra el poder de los medios de comunicación masiva si se utilizan para programas de promoción de la salud. Es decir, éstas deberían adquirir las características de mercado que han utilizado con éxito tantas y tantas empresas privadas. Ante la limitación económica para hacerlo, se deben establecer alianzas estratégicas con las empresas privadas involucradas en el proceso de salud. Contribuiríamos a su beneficio económico, pero sin duda también conseguiríamos el objetivo que el sector salud se ha planteado, el de salud para todos. La única condición es que no se pongan en cuestionamiento o peligro, en ningún momento, los intereses y principios éticos del sector público encargado de la salud. Los resultados de este trabajo muestran que así fue durante el periodo en el cual se llevó a cabo. Por otra parte, se deben idear opciones para promocionar la lucha contra el tabaco. El uso de las imágenes en una de sus expresiones menos conocidas, es decir, aquella que se utiliza en campañas para la salud, es una de ellas. Creemos que el recurso de las imágenes puede explo- tarse conjuntando el ingenio de sus creadores con estrategias de difusión, como la de una galería en donde se expongan carteles para promover la salud.

\section{Referencias}

1.W orld Health 0 rganization. Tobacco or Health: A glo bal status report. Ginebra:W HO, 1997.

2.W orld Bank. Curbing the epidemic: G overnments and the economics of to bacco control. W ashington, D.C.:W orld Bank, 1999.

3. Secretaría de Salud, Secretaría de Prevención y Control de Enfermedades, Dirección General de Epidemiología, Instituto Mexicano de Psiquiatría, Consejo $\mathrm{N}$ acional $\mathrm{C}$ ontra las A dicciones. Encuesta $\mathrm{N}$ acional deA dicciones. Tabaco. México, D.F.: SSA, 1998.

4. Gilpin EA, Pierce JP.Trends in adolescent smoking initiation in the US: Is tobacco marketing an influence? Tobacco Control 1997;6:122-127.

5. Difranza J, Richards J, Paulman PM, W olf-G illespie MA, Fletcher C, Jaffe RD et al. RJR N abisco's cartoon camel promotes camel cigarettes to children. JA MA 1991;266:3149-3153.

6. Centers for Disease Control and Prevention. Cigarette advertising. United States, 1998. MMW R Morb Mortal W kly Rep 1990;39(16):261265.

7. Federal Trade Comission. Report to Congress for 1997: Pursuant to the Federal Cigarette Labeling and Advertising Act. En: U.S. Department of Health and Human Services, ed. W ashington: Trade Commission, 1999. Reducing tobacco use: A Report of the Surgeon General. Atlanta (GA): U.S. Department of Health and Human Services, Centers for Disease Control and Prevention, $\mathrm{N}$ ational $\mathrm{C}$ enter for $\mathrm{C}$ hronic D isease Prevention and Health Promotion, 0 ffice on Smoking and Health, 2000.

8. International Marketing Services, Health. Mercado Farmacéutico versión México. Analisis de los boletines correspondientes a los periodos enero 1998 - mayo 1999, y junio 1999 - mayo 2000.

9. Sansores RH, Valdelamar FR, Giraldo FL, Ramírez-Venegas A, VillalbaCaloca J. Impact of a gallery of posters on quitting smoking.Tobacco C ontrol 1998;7(4):338-339.

10. Sansores RH, Córdoba-Ponce MP, Espinosa-Martínez M, Herrera-Kiengelher L, Ramírez-Venegas A, Martínez-Rossier LA et al. Evaluación del Programa Cognitivo-C onductual para D ejar de Fumar del Instituto $\mathrm{N}$ acional de Enfermedades Respiratorias. Rev IN ER 1998;11(1):29-35.

11.Villalba-C aloca J, Espinosa M, Sansores RH. C línicas de Tabaquismo. Rev IN ER 1999;12(2):83-86.

12. Goldman LK, Glantz SA. Evaluation of antismoking advertising campaigns. JAMA 1998;279:772-777.

13. Prochaska J0, Goldstein MG. Process of smoking cessation. Implications for clinicians. Clin Chest Med 1991;12(4):727-735. 